\title{
Development of an Adaptive Controller for Grid- connected Power Electronic Converter
}

\author{
Khalid Yahia, ${ }^{1, *}$, Ramani Kannan ${ }^{2}$, Nor Zaihar Yahaya ${ }^{3}$, Vijanth Sagayan Asirvadam ${ }^{4}$ \\ Department of Electrical and Electronics Engineering, Universiti Teknologi PETRONAS, Seri \\ Iskandar 32610, Malaysia
}

\begin{abstract}
Power electronics converter (PECs) has become an attractive replacement for the conventional inverter in grid-tied photovoltaic (PV) applications. This is due to improved the transient performance and provided better power quality. In this paper, an improved controller and a novel topology for a PEC is proposed. In this paper, an improved controller and a novel topology for a PEC is proposed. The proposed PEC topology is based on the three-level converter and adaptive PI with a fuzzy logic controller (API-FLC). The PEC with the novel controller is designed to achieve constant DC link voltages and sinusoidal current and voltage with near unity power factor when operating in different conditions. In order to evaluate the validity of the proposed PEC, the model was simulated by MATLAB/Simulink Toolbox. The results obtained with the proposed converter gives a better dynamic performance and improved power quality compared to the conventional converter.
\end{abstract}

\section{Introduction}

Recently, the photovoltaic (PV) power generation system has been focused as one of the most significant energy sources due to the rising concern about global warming, and the increase of electrical power consumption $[1,2]$. Photovoltaic solar power is now, after hydro and wind power, the third most important renewable energy source in terms of globally installed capacity [3]. In addition, the PV module has no moving parts, which have made it a very robust, long lifetime and low maintenance device. In the photovoltaic systems, power electronics converters (PECs) are the key enable parts. Energy is transferred from the PV, through power electronics converter, then finally to the load. In general, PV power generation system includes solar arrays and power conversion unit [4].

Generally, several studies with a focus on the design topologies and control of PEC have been carried out in [5-7]. However, most of the study used series and parallel connection of the power electronic converter to achieve high voltage level, which results in possibly lower efficiency and reliability, and the conventional PI controller was used. Several control strategies have been proposed in the previous work in order to obtain a well-regulated output voltage from PEC converters characterized by time variant dynamics, variable supply voltage, and non-linear loads. Among these control, strategies are PID controller, fuzzy logic controller, fuzzy-PI techniques that found their application in power converters linear control

* Corresponding author: khalidy34@yahoo.com 
like PID control, and neural network control [8-10]. The fuzzy logic control and neural network control have provided improved control action compared to the linear PID controller, but they usually have issues of developmental difficulties, high computational complexity, and large processing power. Based on the literature review, this paper introduces new topology and modern control strategy based on an adaptive PI control to improve the dynamic response and power quality of PEC in PV grid-connected applications.

\section{The proposed topology}

The proposed topology of the PEC is presented in Figure 1. The PEC accepts DC input voltage and provides a three-phase output voltage. It has two stages including; an isolation stage, and an output stage. The isolation stage consists of two half-bridge, three-level converters connected with a high-frequency transformer between them. The second stage is the output stage which consists of a three-phase, three-level PWM converter, which acts as an inverter used to convert the DC voltage to AC.

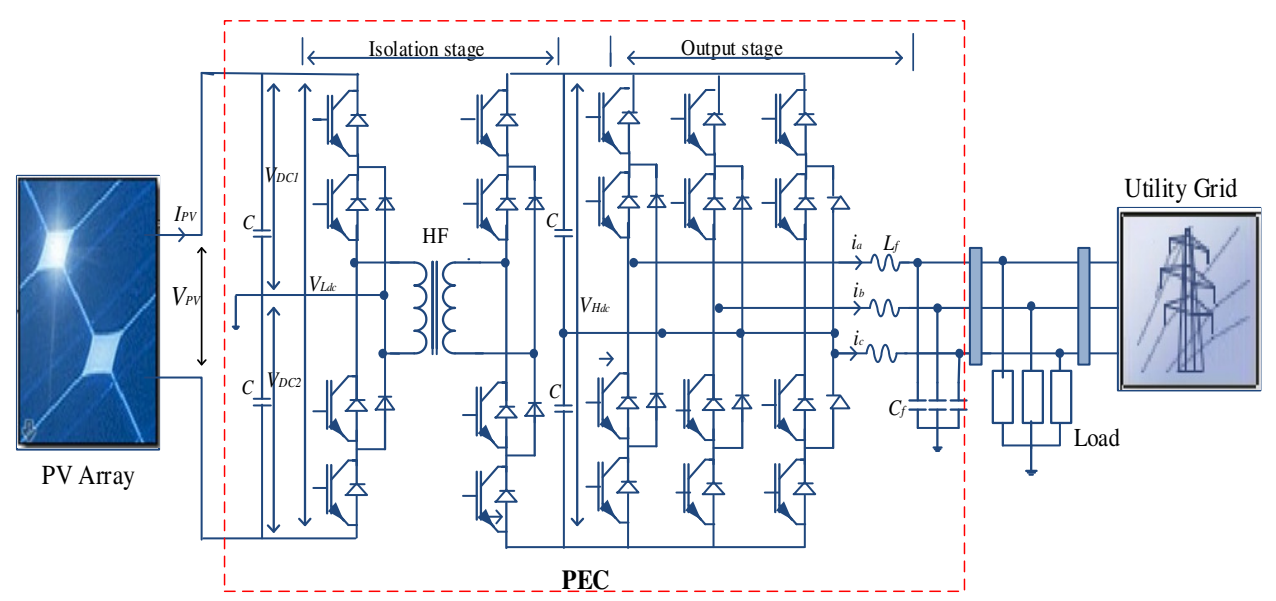

Fig. 1. The proposed topology of PEC

The proposed PEC in this study uses a three-level converter in the isolation stages and output stage to achieve a high voltage level as well as to improve the power quality of the PEC. The level-converter has advantages such as better sinusoidal waveform, lower switching loss, and less voltage stress across semiconductor devices than a two-level converter. Furthermore, it has a better voltage balance and a simple control circuit than Cascaded H-Bridge converter [11, 12].

\section{Modeling of PV Array and Controller design for the PEC}

Solar PV cell is the basic unit of solar PV array/panel, they are combined in series and parallel to achieve require voltage and current level. Since PV arrays are composed of large numbers of solar cells, it is impractical to simulate all the cells individually in a PV array. Therefore, the solar module can be considered as the building block for the large PV array. The equivalent circuit of a PV model is indicated in Figure 2. The single diode model represented by a constant current source connected in parallel with a diode and the non-idealities are represented by the insertion of the resistance series resistance $\left(R_{S}\right)$ and parallel resistance $\left(R_{P}\right)$ [13]. 


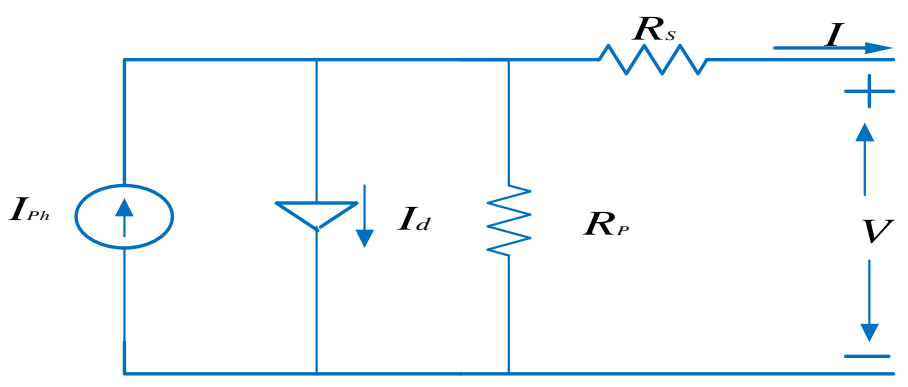

Fig. 2. Single diode model of a PV cell

The basic V-I characteristic of the PV module is written as follows:

$$
I_{P V}=I_{p h}-I_{s a}\left[e\left(\frac{V_{P V}+R I_{P V}}{V_{t} a}\right)-1\right]-\frac{V_{P V}+R_{S} I_{P V}}{R_{P}}
$$

where $V_{P V}$ and $I_{P V}$ represent the PV cell output voltage and current, respectively. $R_{S}$ and $R_{P}$ are the equivalent series and shunt resistances of the cell, respectively. $I_{P h}$, is the light generated current, $I_{s a}$, is the reverse saturation current. $V_{t}=k T / q$ is the thermal voltage of the diode, $q$ is the electron charge $(1.6 \times 10-19 \mathrm{C}) ; a$ is the ideality factor of the diode, $k$ is Boltzmann constant $1.38 \times 10-23 \mathrm{JK}-1$, and $T$ is the temperature (in Kelvin).

There are several types of commercial PV solar from different companies with different voltage and power rating. Some commercial-grade photovoltaic panels available in the market have been studied and Canadian Solar CS5P-250M solar panel has chosen. This panel has the specifications as presented in Table 1. The PV is simulated related parameters of the combined PV array have been calculated as the specification of one single panel shown in Table 1 for simulation purpose. To produce high power capacity the PV system, series and parallel combinations of a photovoltaic array (PVA) have been used. The $1 \mathrm{~kW} \mathrm{PV}$ array consists of 2 series and 2 parallel module $(2 * 2 * 250.3=1.1 \mathrm{~kW})$.

Table 1. Canadian Solar CS5P-250M (250W) solar panel specifications

\begin{tabular}{|c|c|}
\hline Parameter & Value \\
\hline Power Rating (Pmax) & $250 \mathrm{~W}$ \\
\hline Rated Voltage (Vmpp) & $48.7 \mathrm{~V}$ \\
\hline Rated Current (Impp) & $5.14 \mathrm{~A}$ \\
\hline Open-Circuit Voltage (Voc) & $59.6 \mathrm{~V}$ \\
\hline Short-Circuit Current (Isc) & $5.49 \mathrm{~A}$ \\
\hline Number of Cells & 96 \\
\hline
\end{tabular}

The solar irradiance is assumed to vary from one irradiance to another irradiance value (e.g. 250,750 , and $1000 \mathrm{~kW}$ or vice versa) as a real changing in irradiation for one day from $7 \mathrm{am}$ 
to $6 \mathrm{pm}$. As the PV output is also strongly dependent on the surrounding temperature, in this work is assumed to have a fixed temperature of $25^{\circ} \mathrm{C}$ during the simulation. Figure 3 . illustrates the current-voltage $(\mathrm{I}-\mathrm{V})$ and power-voltage $(\mathrm{P}-\mathrm{V})$ characteristics of the $\mathrm{PV}$ array simulated curves obtained from MATLAB/Simulink for the $1000 \mathrm{~W}$ and the $100 \mathrm{~kW}$ respectively for di $\square$ erent irradiation.
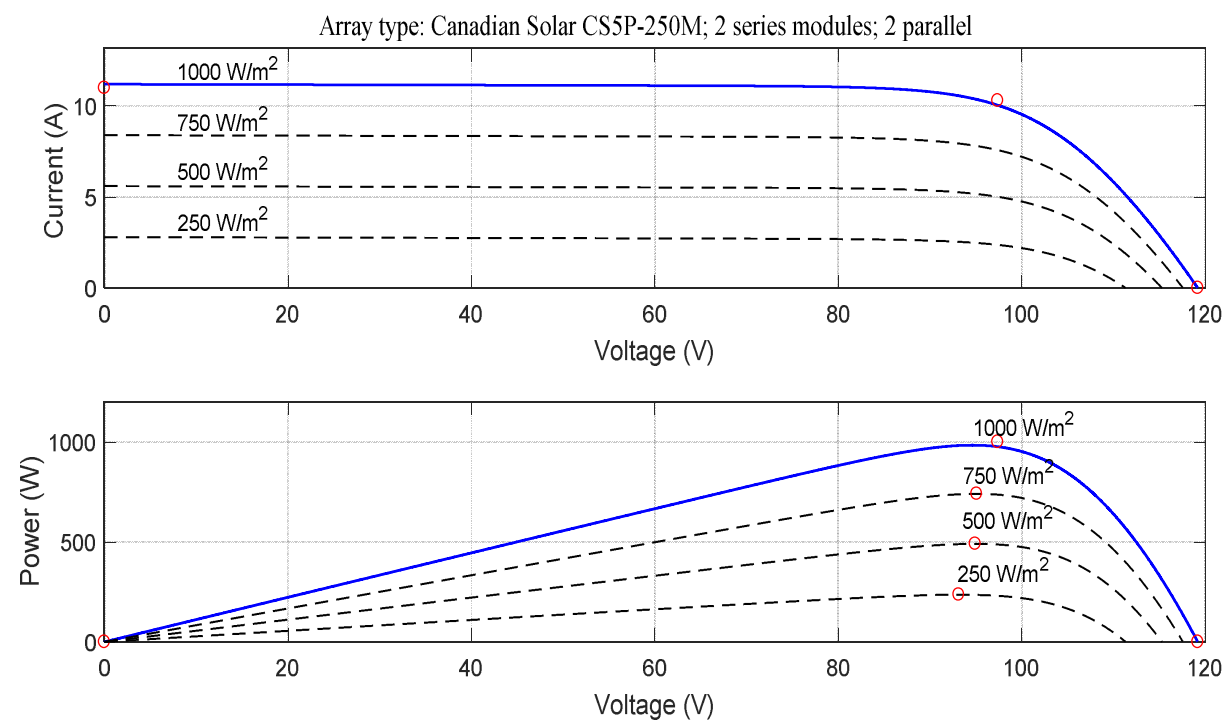

Fig. 3. I-V and P-V curve at various irradiances for a $100 \mathrm{~W}$ PV array model

Control is the heart of PEC, each part has an independent controller, isolation stage controller, and output stage controller. The structure of the proposed API-FLC is illustrated in Figure 4. The main controller is the PI which controls the PEC when operating under steady state. When a large disturbance occurs due to load current change or short-circuit faults, the FLC automatically re-sets the PI gains based on the error $(e)$ signal and the change of error $(\Delta e)$ signal. The fuzzy adapter comprises two inputs and outputs signals (see Figure 4). The first input is the error, $(e)$, which is the difference between the reference and measured values, and the second input is the change of error $\Delta e$, which is the first-time difference of the error. The two output signals $\left(\left(K_{P}^{\prime}\right)\right.$ and $\left.\left(K_{I}^{\prime}\right)\right)$ are adaptive signals for PI parameters. By detecting the possible deviation from the inputs of the FLC, it is possible to automatically update the PI controller parameters for set-point changes and load disturbances.

the

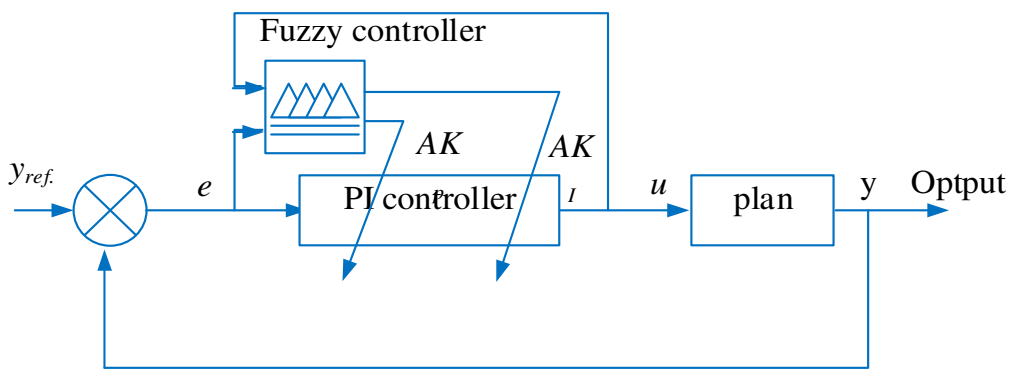

Fig. 4. PI controller adapted with fuzzy controller 
Figure 5 illustrates the controller of the isolation stage based on API- FLC. The low DC link voltage $\left(V_{L d c}\right)$ compared to the reference voltage $\left(V_{P V-r e f}\right)$, which generates by the maxim power point taking (MPPT) and then the estimated error is passed to API-FLC to generate the phase-shift control signal to drive the half-bridge three-level converters. The structure of the proposed adaptive controller for the output stage based on the API- FLC strategy is shown in Figure 6.

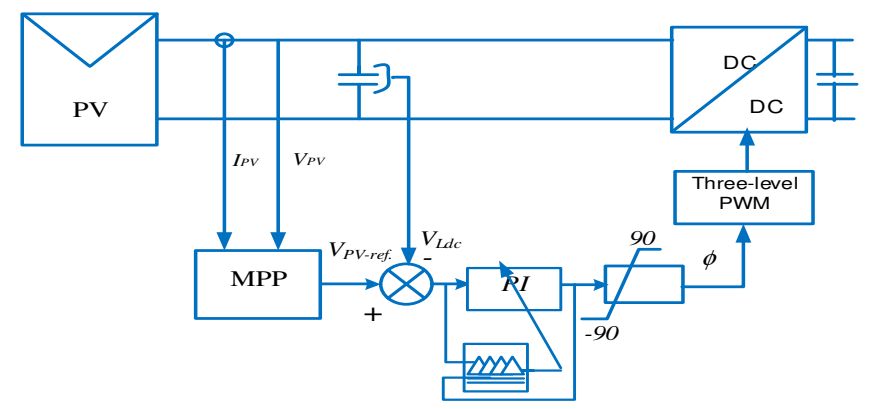

Fig. 5. The isolation stage control based on PI-AFLC

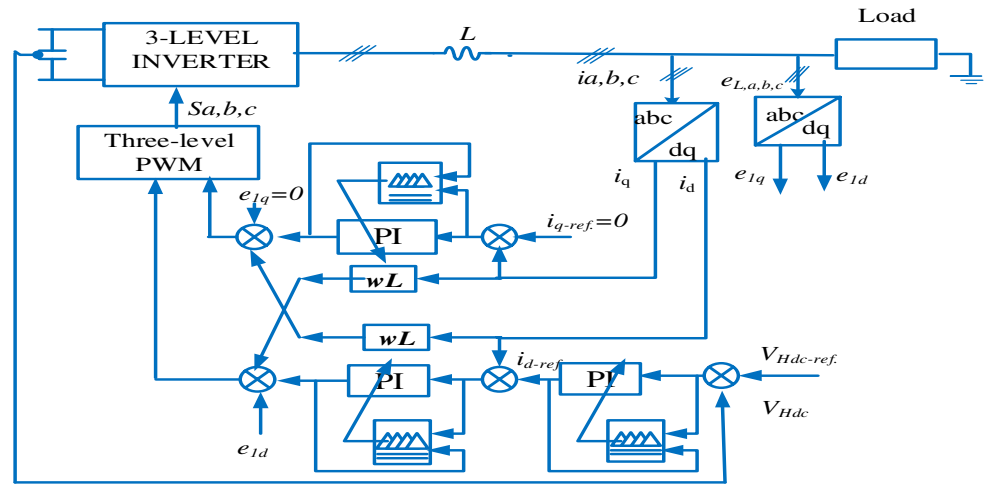

Fig. 6. Output stage control of the PEC based on PI-AFLC

MATLAB/SIMULINK software was used to simulate the PEC by building the circuit model in the Simulink environment using the Sim-power block tools as presented in Figure 7. The simulation parameters for the PEC system considered for this study are provided in Table 2.2 .

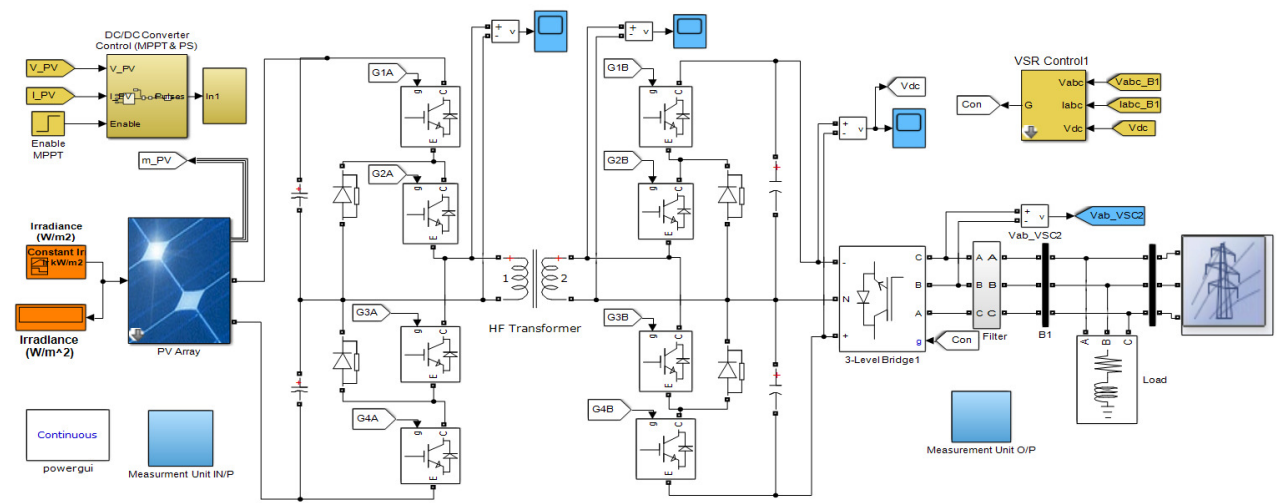

Fig. 7. Simulation block diagram for the proposed PEC 
Table 2. PEC specifications

\begin{tabular}{|l|l|}
\hline \multicolumn{1}{|c|}{ Parameter } & \multicolumn{1}{c|}{ Value } \\
\hline Transformer power rating & $1 \mathrm{kVA}$ \\
\hline Input DC voltage & $96 \mathrm{~V}$ \\
\hline Output voltage & $240 \mathrm{~V}$ \\
\hline Low DC link capacitance & $5000 \mu \mathrm{F}$ \\
\hline High DC link capacitor & $200 \mu \mathrm{F}$ \\
\hline High output voltage DC link & $680 \mathrm{~V}$ \\
\hline Isolation stage switching frequency & $10 \mathrm{kHz}$ \\
\hline Output stage switching frequency & $3 \mathrm{kHz}$ \\
\hline Load & $1 \mathrm{~kW}$ \\
\hline
\end{tabular}

\section{Results and discussion}

The dynamic response of the PEC is tested under changes in solar irradiation levels, a solar irradiation curve with ramp changes is generated as presented in Figure 8. The irradiation increases gradually from $750 \mathrm{~W} / \mathrm{m}^{2}$ at $2.5 \mathrm{~s}$, until it reaches $1000 \mathrm{~W} / \mathrm{m}^{2}$ at $3.0 \mathrm{~s}$ maintains at this value for a period of $0.1 \mathrm{~s}$, and drops slowly to $750 \mathrm{~W} / \mathrm{m}^{2}$ at $4.5 \mathrm{~s}$. The input-output voltage and current when the PV array irradiation change happens are shown in Figure 9. As seen in the figure, the input current increase and decrease depending on the changing in the radiation, while the input voltage varies around 97 and 95 voltage. The output current increase as the input power increases, whereas the output voltage waveforms are not affected by the irradiation change; this means that the PEC controller noticed a change in DC bus and adjusted the modulation index. This was kept the output voltage constant and in phase with current, this means the near unity power factor was achieved, with less harmonic distortion of THD 1.8\%, which was less than IEEE standard 5\%.

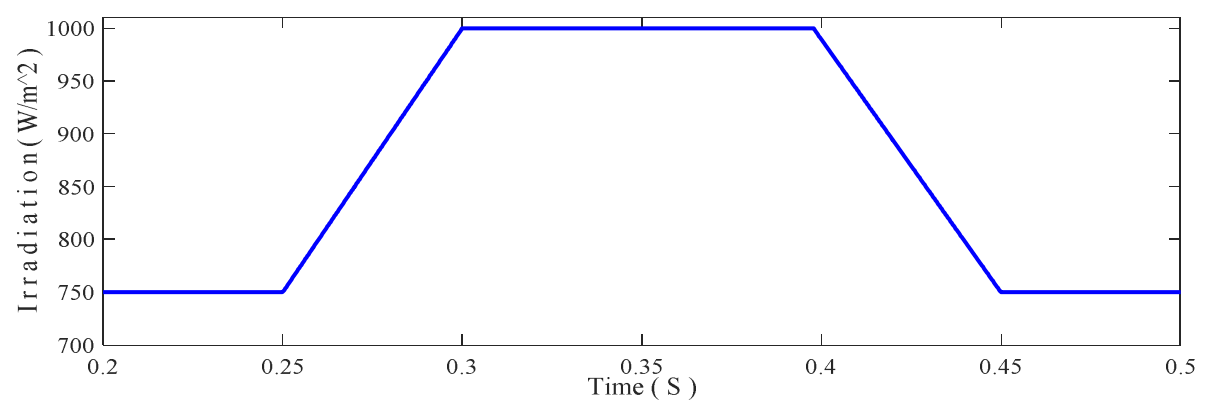

Fig. 8. Ramp change of irradiation 

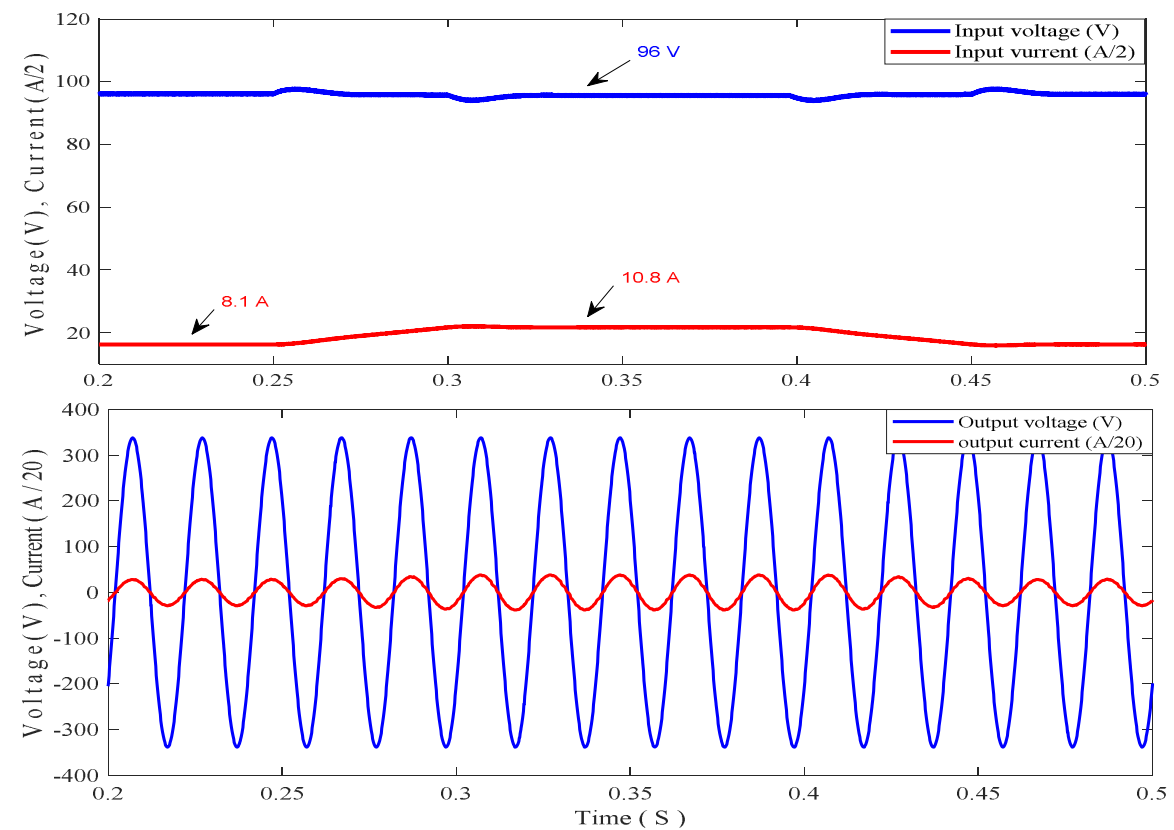

Fig. 9. Input voltage and current under the voltage sag Output voltage and current under the voltage sag

Figure 10 shows the high DC link voltage for the PEC during the irradiation change in the PV array. The high DC link voltage not affected by the change and remains contents as adjusted in the reference value of the output controller. Figures 11 shows the response of the input and output power when the irradiation change occurred. The input power changed from 745 to $1000 \mathrm{~W}$ and the change back to 745 , while the output power change from 735 to 996 $\mathrm{W}$ and vice versa. The results illustrate that the proposed PEC with PI controller mitigates the irradiation change and generates a balanced output voltage by modifying the modulation index of the converter to increase voltage during the change. In addition, the voltage and current were in phase and almost sinusoidal.

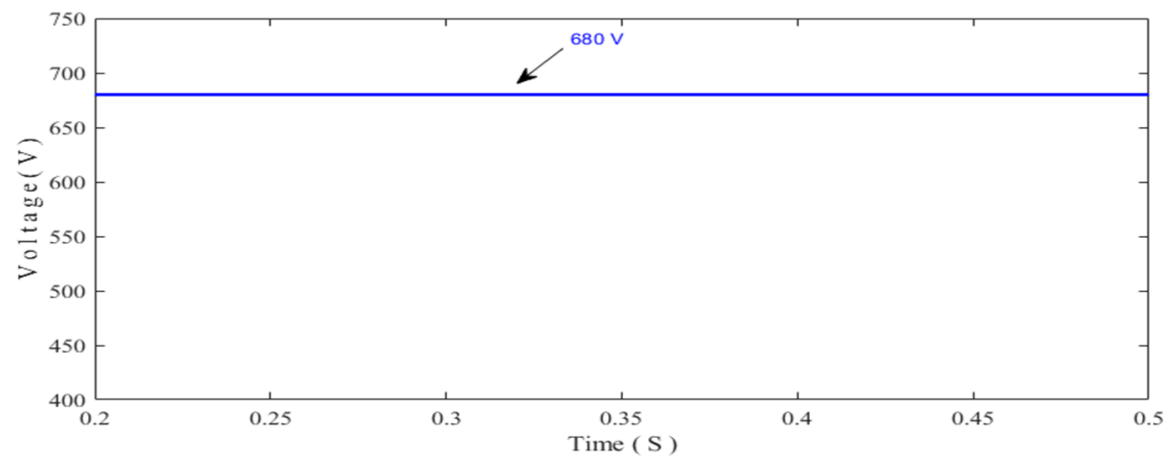

Fig. 10. PEC high DC link voltage under variable irradiation 


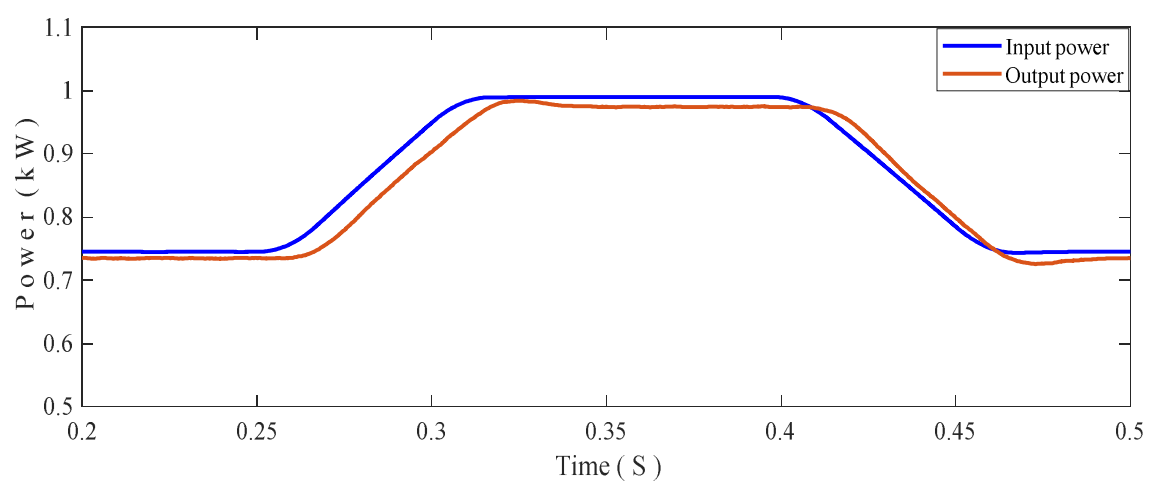

Fig. 11. PEC input and output power under irradiation change

\section{Conclusion}

In this paper, a novel topology of a power electronic converter for PV grid-connected based on a three-level converter and an adaptive PI controller was proposed. The performance of the proposed converter under different irradiation has been investigated with the developed controller. Constant DC links voltage was achieved during the irradiation change, and near unity power factor with less total harmonic distortion (THD) was achieved. Therefore, the proposed converter and developed API-FLC has the advantage of providing a stable control system in both steady and dynamic conditions.

\section{References}

1. M. Islam, S. Mekhilef, M. Hasan, Renewable and Sustainable Energy Reviews,. 45: p. 69-86, (2015)

2. M. Islam, N. Afrin, S. Mekhilef, IEEE Transactions on Sustainable Energy, 7(3): p. 1205-1215.( 2016)

3. M. Moonem, Modular multi-level power converter for large scale grid-connected photovoltaic system, The University of Texas at San Antonio, (2016)

4. H. Xiao, S. Xie, IEEE Transactions on Electromagnetic Compatibility, 52(4): p. 902-913,(2010)

5. Y. Li, J. Han, Y. Cao, Y. Li, J. Xiong, D. Sidorov, D. Panasetsky, International Journal of Electrical Power \& Energy Systems, 85: p. 153-163, (2017)

6. X. Wang, J. Liu, S. Ouyang, T. Xu, F. Meng, S. Song, IEEE Transactions on Power Electronics, 31(3): p. 2002-2011, (2016)

7. L. Liu, H. Li, Y. Xue, W. Liu, IEEE Transactions on Power Electronics, 30(1): p. 176-187, (2015)

8. A. fekik, H. denoun, N. benamrouche, N. beyahia, M. zaouia, S. haddad, International Journal of Circuits, Systems and Signal Processing, 9: p. 7, (2015)

9. E. Çelik, A. Dalcali, N. Öztürk, R. Canbaz, An adaptive PI controller schema based on fuzzy logic controller for speed control of permanent magnet synchronous motors, In Power Engineering, Energy and Electrical Drives (POWERENG), Fourth International Conference, pp. 715-720, (IEEE 2013)

10. K. Ahmed, N. Yahaya, O. Ibrahim, International Journal of Advanced And Applied Sciences, 5(5): p. 34-39, (2018).

11. W. Oh, S. Han, S. Choi, G. Moon, Three phase three-level PWM switched voltage source inverter with zero neutral point potential, in Power Electronics Specialists Conference, 2004. PESC 04. 2004 IEEE 35th Annual, (IEEE 2004) 
12. K. Ahmed, N. Yahaya, O. Ibrahim, International Journal of Power Electronics and Drive Systems (IJPEDS), 2017. 8(4): p. 1603-1611.

13. M. Brito, L Galotto, L. Sampaio,G. Melo, C. Canesin, IEEE transactions on industrial electronics, 2013. 60(3): p. 1156-1167. 